3. Kotb, E. (2014), "The biotechnological potential of fibrinolytic enzymes in the dissolution of endogenous blood thrombin", Biotechnology progress.

4. Cyrille Orset et al (2007), Mouse Model of In Situ Thromboembolic Stroke and Reperfusion,
Stroke.38:2771-2778.

5. Clark W, Gunion-Rinker $L$, Lessov $N$, Hazel $K$, Macdonald RL. Citicoline treatment for experimental intracerebral hemorrhage in mice. Stroke. 1998, 29, pp. 2136-2140.

\title{
ĐÁNH GIÁ KẾT QUẢ LÂU DÀI CỦA PHẪU THUÂT PHACO CÓ ĐĂT THỦY TINH THỂ NHÂN TẠO TẠI BỆNH VIỆN ĐA KHOA TỈNH QUẢNG NINH
}

\author{
Lưu Đức Hà1, Cung Hồng Sơn ${ }^{2}$, \\ Vũ Anh Tuấn ${ }^{3}$, Lương Thị Hải Hà ${ }^{4}$
}

\section{TÓM TẮT}

Mục tiêu: Đánh giá kết quả lâu dài của phẫu thuật phaco có đặt thủy tinh thể nhân tạo tại Bệnh viện đa khoa tỉnh Quảng Ninh. Đối tượng và phương pháp: Nghiên cứu được tiến hành trên 123 mắt được phẩu thuật Phaco và đăt thủy tinh thể nhân tạo tai BV Đa khoa tỉnh Quảng Ninh. Nghiên cứu mô tả cắt ngang. Kết quả: Tuối trung bình của bệnh nhân là $71,70 \pm 7,75$, tỷ lệ nam nhỏ hơn nữ tương ứng là $47,8 \%$ so với $52.2 \%$, phần lớn là đục thủy tinh thể do tuổi già 115 mắt $(93,5 \%)$, thị lực sau chỉnh kính có tới 106 mắt $(86,2 \%)$ thị lực trền $20 / 40$, số mắt có độ loan 1.00 đến $\leq 2.00$ Diop trước phấu thuât là 31 mắt $(25,2 \%)$, tại thời điểm nghiên cứu là 46 mắt $(37,4 \%)(p<0,05)$, có 5 biến chứng phát hiện ở thời điểm nghiên cứu: Đục bao sau là biến chứng gặp nhiều nhất với $69,1 \%$, tiếp đến là xơ hóa co kéo vòng xé bao $52,8 \%$, rách bao sau là 3,3\%. Kết luận: Biến chứng lâu dài gặp nhiều nhất sau phẫu thuật là loan thị, đục bao sau, xơ hóa co kéo vòng kéo bau và rách bao sau

Từ khóa: Thị lực, phaco, thủy tinh thể nhân tạo,...

\section{SUMMARY}

\section{ASSESSMENT OF LONG-TERM RESULTS OF PHACO SURGERY IN GENERAL HOSPITAL QUANG NINH PROVINCE}

Objective: Assessment of long-term results of Phaco surgery in general hospital Quang Ninh province. Methods: The study was conducted on 123 eyes of 67 patients were been surgery Phaco in general hospital Quang Ninh province. Cross-sectional descriptive study. Results: The mean age of the patients was $71.70 \pm 7.75$, the men were smaller than women $(47.8 \%$ and $52.2 \%)$, most of them were cataracts due to old age 115 eyes $(93.5 \%)$, ), good

\footnotetext{
${ }^{1}$ Bệnh viện Đa khoa Tỉnh Quảng Ninh,

${ }^{2}$ Bênh viện Mắt Trung Uơng

3 Trường Đại học Y Hà Nội,

${ }^{4}$ Trường Đại học Y Dược Thái Nguyên

Chịu trách nhiệm chính: Lưu Đức Hà

Email: dr.luuducha@gmail.com

Ngày nhận bài: 9.9.2021

Ngày phản biện khoa học: 29.10.2021

Ngày duyệt bài: 10.11.2021
}

visual acuity 106 eyes (86.2\%), the eyes with astigmatism 1.00 to $\leq 2.00$ Diop before surgery was 31 eyes $(25.2 \%)$, the study included 46 eyes $(37.4 \%)$ $(p<0.05)$, there were 5 complications detected: opaque posterior capsule was the most common complication with $69.1 \%$, pull posterior capsule was $52.8 \%$ and gash posterior capsule was $3.3 \%$. Conclusion: The most common long-term complications after surgery are astigmatism, opaque posterior capsule, gash posterior capsule.

Key words: Vision acuty, phaco, IOL,...

\section{I. ĐẶT VẤN ĐỀ}

Bênh đục thủy tinh thể là môt trong nhũng nguyên nhẩn hàng đầu gây mù lìa ở Việt Nam cũng như trên thế giới. Điều trị nội khoa đục thủy tinh thể chỉ có tác dụng rất hạn chế, một số thuốc như sorbitol, aspirin, vitamin $C$ và $E$ chủ yếu được sử dung để dự phòng đục thủy tinh thể bằng chế độ dinh dưỡng hợp lý và tránh các yếu tố nguy cơ [1],[2]. Điều trị ngoại khoa đục thủy tinh thể mới giải quyết triệt để được bệnh và là môt trong những vấn đề có tính chất toàn cầu nhằm hạ thấp tỷ lệ đục thủy tinh thể, giảm tỷ lệ mù lòa, nâng cao chất lượng lao động và cuộc sống của con người [3],[4].

Ngày nay, với sự tiến bộ không ngừng của vi phẫu thuật, phẫu thuật làm nhuyễn thủy tinh thể bằng năng lượng siêu âm (Phacoemulsification) gọi tắt là phẫu thuật Phaco là phẫu thuật khá an toàn, ít biến chứng, phục hồi thị lực nhanh chóng và tối đa cho người bệnh. Phương pháp này có rất nhiều ưu điểm: vết mổ nhỏ, do đó giảm độ loạn thi; vết mổ nhanh liền, rút ngắn thời gian hậu phấu; đem lại thị lực cao cho bệnh nhân ngay từ những ngày đầu sau mổ do vậy là lựa chọn điều trị đục thể thuỷ tinh hàng đầu của các bác sĩ nhãn khoa [1],[4].

Bệnh võng mạc đái tháo đường là một trong những nguyên nhân hàng đầu gây mất thị lực trên thế giới. Nếu không được điều trị và phát hiện kịp thời sẽ gây ra những tổn thương nặng nề ở đáy mắt như: phù hoàng điểm, tân mạch 
võng mạc, xuất huyết dịch kính, xuất huyết võng mạc,... dẫn đến tình trạng mù lòa gây ảnh hưởng nghiêm trọng đến chất lượng cuộc sống của người bệnh [2].

Từ năm 2011, Khoa mắt Bệnh viện đa khoa tỉnh Quảng Ninh đã bắt đầu triển khai phẫu thuật Phaco trong điều trị đục thủy tinh thể, hàng năm có trên 100 bệnh nhân được phẫu thuật Phaco có đặt thủy tinh thể nhân tạo, số bệnh nhân tăng dần theo thời gian. Tuy nhiên chưa có nghiên cứu nào mang tính hệ thống để tổng kết, đánh giá quả lâu dài của kỹ thuật này. Chính vì vậy, chúng tôi tiến hành nghiên cứu đề tài này nhằm mục tiêu: "Đánh giá kết quả lâu dài của phẫu thuật phaco có đặt thủy tinh thể nhân tạo tại Bệnh viện đa khoa tỉnh Quảng Ninh"

\section{II. ĐỐI TƯợNG VÀ PHƯƠNG PHÁP NGHIÊN CỨU \\ 2.1. Đối tượng nghiên cứu}

2.1.1. Thời gian nghiên cứu. Nghiên cứu được tiến hành tại Bệnh viện đa khoa tỉnh Quảng Ninh trong thời gian từ tháng 07/2020 đến tháng 08 năm 2021.

\subsubsection{Tiêu chuẩn lựa chọn}

- Bệnh nhân đã phấu thuật Phaco đặt thủy tinh thể nhân tạo tại Bệnh viện đa khoa tỉnh Quảng Ninh, từ tháng 1/2016 đến tháng 12/2019.

- Có đầy đủ thông tin liên lạc còn hiệu lực của bệnh nhân.

- Bệnh nhân đồng ý tham gia nghiên cứu.

- 100\% bệnh nhân lựa chọn nghiên cứu được đặt thủy tinh thể nhân tạo đợn tiêu cự.

\subsubsection{Tiêu chuẩn loại trừ}

- Các hồ sơ không đầy đủ và rõ ràng.

- Tại mắt: sẹo giác mạc, mắt chấn thương, mắt viểm màng bồ đào, tăng nhãn áp.

- Toàn thân: Bệnh nhân già yếu, không thể tham gia nghiên cứu.

\subsection{Phương pháp nghiên cứu}

2.2.1. Phương pháp nghiên cứu: Nghiên cứu mô tả cắt ngang

2.2.2. Phương tiện nghiên cứu: Bảng thị lực Landolt, hộp thử kính, bộ đo nhãn áp kế, sinh hiển vi khám, kính Volk, thuốc giãn đồng tử Mydrin-P, máy đo khúc xạ tự động, đèn soi bóng đồng tử,...

\subsubsection{Các bước tiến hành}

- Liên hệ với bệnh nhân đề nghị tham gia nghiên cứu và hẹn khám.

- Khám cho bệnh nhận theo hẹn để thu thập thông tin.

- Thu thập thông tin: Mời các bệnh nhân được phẫu thuật từ năm 2016-2019 đến khám lại, các thông tin phẫu thuật từ bệnh án lưu.
- Khám hiện tại: đo thị lực, đo khúc xạ, nhãn áp, đánh giá độ nhạy cảm tương phản,...

- Khám thực thể: Giác mạc, đồng tử, tiền phòng, đánh giá tình trạng bao trước và bao sau, tình trạng thủy tinh thể nhân tạo, soi đáy mắt,...

\subsubsection{Các chỉ tiêu nghiên cứu}

- Giới: Nam hay nữ

- Tuổi: < 60 tuổi (người trẻ) và trên 60 tuổi (người già).

- Thị lực nhìn xa và nhìn gần

- Chức năng thị giác trước và sau phẫu thuật

- Biến chứng gần sau mổ

- Kỹ thuật mố, loại thủy tinh thể nhân tạo đặt cho bệnh nhân

- Đánh giá chức năng thị giác tại thời điểm khám.

- Đánh giá thị lực: Dựa vào bảng phân loại mức độ giảm thị lực của tổ chức y tế thế giới WHO:

Rất tốt: $\geq 20 / 25$

Tốt: 20/40 - 20/30

Khá : 20/60 - 20/50

Trung bình: 20/200 - 20/70

Kém : $\leq 20 / 200$

- Đánh giá loạn thị giác mạc chia 4 mức độ: Nhẹ dưới 1 Diop, vừa từ 1 đến 2 Diop, nặng từ 2.25 đến 3 Diop, rất nặng trên 3 Diop.

- Đánh giá sự thay đổi loạn thị do phẫu thuật: Độ loạn thị tăng: hiệu số này $>0$, độ loạn thị giảm: hiệu số này $<0$, độ loạn thị không đổi: hiệu số này $=0$.

- Khúc xạ tồn dư sau phẫu thuật

- Nhãn áp trước và sau phẫu thuật, nhãn áp hiện tai.

- Đánh giá mức độ lệch thủy tinh thể nhân tạo.

- Đánh giá sự hài lòng của người bệnh

2.2.5. Phương pháp xử lý số liệu: Sử dụng phần mềm SPSS 20.0 và xử lý số liệu theo phương pháp thống kê y học.

\section{KẾT QUẢ NGHIÊN CỨU}

Trong nghiên cứu này, chúng tôi nghiên cứu trên 123 mắt của 67 bệnh nhân trong đó có 56 bệnh nhân được phẫu thuật 2 mắt và 11 bệnh nhân phẫu thuật 1 mắt, chúng tôi thu được kết quả như sau:

\section{1. Đặc điểm chung của bệnh nhân}

Bảng 1: Đặc điểm chung cửa bệnh nhân

\begin{tabular}{|c|c|c|c|c|}
\hline$\pi$ & \multicolumn{2}{|c|}{ Đăc điểm } & Số lương & Tỷ lệ \\
\hline \multirow{3}{*}{1} & \multirow{3}{*}{ Tuổi } & $\leq 60$ & 6 & 8,96 \\
\hline & & $>60$ & 61 & 91,04 \\
\hline & & \multicolumn{3}{|c|}{$\begin{array}{c}\text { TB } 71.70 \pm 7.75, \text { min: } 56 ; \\
\text { max: } 88: \text { mode: } 72\end{array}$} \\
\hline \multirow{2}{*}{2} & \multirow{2}{*}{ Giới } & Nam & 32 & 47.8 \\
\hline & & Nũ & 35 & 52,2 \\
\hline
\end{tabular}


Tuổi trung bình của bệnh nhân là $71,70 \pm$ 7,75 , thấp nhất 56 cao nhất 88 tuổi. Số bệnh nhân có tuổi trên 60 chiếm tỷ lệ lớn $(91,04 \%)$. Tỷ lệ nam nhỏ hơn nữ tương ứng là $47,8 \%$ so với $52.2 \%$.

\subsection{Hình thái đục thủy tinh thể}

Bảng 2: Hinh thái đuc thủy tỉnh thê

\begin{tabular}{|c|c|c|}
\hline Phân loại & Số lượng & Tỷ lệ(\%) \\
\hline Đục TT tuổi già & 115 & 93,5 \\
\hline Đục TiT tính chất bệnh lý & 2 & 1,6 \\
\hline Đục TTT do Steroid & 6 & 4,9 \\
\hline Tống & $\mathbf{1 2 3}$ & $\mathbf{1 0 0}$ \\
\hline
\end{tabular}

Trong tống số 123 mắt được nghiên cứu, phân lớn là đục thủy tinh thể do tuổi già 115 mắt $(93,5 \%)$, còn lại là do bệnh lý và Steroid 8 mắt $(6,5 \%)$.

3.3. Đặc điểm thị lực tại thời điểm khám của đối tượng nghiển cứu

Bảng 3. Thị lực tai thời điểm khám của đôii tượng nghiên cứu

\begin{tabular}{|c|c|c|}
\hline Thị lực & n (bệnh nhân) & Tỷ lệ \% \\
\hline$<20 / 200$ & 1 & 0,8 \\
\hline $20 / 200-20 / 70$ & 4 & 3,2 \\
\hline $20 / 60-20 / 50$ & 12 & 9,8 \\
\hline $20 / 40-20 / 30$ & 55 & 44,7 \\
\hline$\geq 20 / 25$ & 51 & 41,5 \\
\hline Tổng & $\mathbf{1 2 3}$ & $\mathbf{1 0 0}$ \\
\hline
\end{tabular}

Thi lực sau chỉnh kính có tới 106 mắt $(86,2 \%)$ thị lực trên $20 / 40$, trong đó nhóm 20/40-20/30 là 44,7\%. Đặc biêtt nhóm $\geq 20 / 25$ chiếm $41,5 \%$. Nhóm $20 / 60-20 / 50$ là $9,8 \%$, Chỉ có 1 mắt $(0,8 \%)$ có thị lực $<20 / 200$.

3.4. Độ loạn thị trước phẫu thuật và tại thời điểm nghiên cứu

Bảng 4: Độ loạn thị trước phẫu thuật và tại thời điểm nghiên cứu

\begin{tabular}{|c|c|c|c|c|}
\hline \multirow{2}{*}{$\begin{array}{l}\text { Độ loạn thị } \\
\text { (Diop) }\end{array}$} & \multicolumn{2}{|c|}{$\begin{array}{c}\text { Trước phầu } \\
\text { thuật }\end{array}$} & \multicolumn{2}{|c|}{$\begin{array}{c}\text { Thời điểm } \\
\text { nghiên cứu }\end{array}$} \\
\hline & Số m & $(\%)$ & Số m & $(\%)$ \\
\hline $0-<1.00$ & 92 & $74,8 \%$ & 77 & $62,6 \%$ \\
\hline $1.00-\leq 2.00$ & 31 & $25,2 \%$ & 46 & $37,4 \%$ \\
\hline$>2.00$ & 0 & 0 & 0 & 0 \\
\hline Trung bình & $\begin{array}{r}\mathrm{T} \\
0,6 \\
\text { Min: } \\
1,75 \text {, }\end{array}$ & $\begin{array}{l}\text { SD: } \\
=0,39 \\
\text {, Max: } \\
\text { de: } 0,5\end{array}$ & $\begin{array}{r}0, \\
\text { Min: } \\
1,75\end{array}$ & $\begin{array}{l}\text { SD: } \\
\pm 0,38 \\
\text { o, Max: } \\
\text { ode: } 0,5\end{array}$ \\
\hline $\mathbf{P}$ & & & 0,05 & \\
\hline
\end{tabular}

Tại 2 thời điểm không có mắt nào có độ loạn thị giác mạc trên 2.00 Diop. Số mắt có độ loạn 1.00- $\leq 2.00$ Diop trước phẫu thuật là 31 mắt $(25,2 \%)$, tại thời điểm nghiên cứu là 46 mắt $(37,4 \%)$. Độ loạn thị giác mạc tại thời điểm nghiên cứu cao hơn trước phẫu thuật $(p<0,05)$

3.5. Triệu chứng chủ quan sau phẫu thuật

\begin{tabular}{|c|c|c|c|}
\hline $\begin{array}{c}\text { Nội } \\
\text { dung }\end{array}$ & Triệu chứng & SL & $\begin{array}{c}\text { Tỷ lệ } \\
\text { \%o }\end{array}$ \\
\hline 1 & Lóa mắt & 52 & 42,3 \\
\hline 2 & Nhìn màu sắc thay đối & 6 & 4,9 \\
\hline 3 & Cảm giác ruồi bay & 91 & 73,9 \\
\hline 4 & Nhìn vật rung rinh & 1 & 0,8 \\
\hline 5 & Triệu chứng khác & 11 & 8,9 \\
\hline 6 & Không triệu chứng & 14 & 11,4 \\
\hline
\end{tabular}

Tại thời điểm nghiên cứu, cảm giác ruôi bay và lóa mắt là hai triệu chứng hay gặp nhất lần lượt là 91 mắt $(73,9 \%)$ và 52 mắt $(42,3 \%)$. Triệu chứng khác chủ yếu là ngứa mắt cộm chiếm $8,9 \%$. Nhìn vật rung rinh xảy ra ít nhất với 1 mắt $(0,8 \%)$. Có 14 mắt (11,4\%) không có triệu chứng.

\subsection{Biến chứng sau phấu thuật}

\section{Bảng 6: Biến chứng sau phấu thuât}

\begin{tabular}{|c|c|c|c|}
\hline $\begin{array}{c}\text { Nội } \\
\text { dung }\end{array}$ & Biến chứng & $\begin{array}{c}\text { Số } \\
\text { lượng }\end{array}$ & $\begin{array}{c}\text { Tỷ lệ } \\
\text { \%ọ }\end{array}$ \\
\hline 1 & Đồng tử méo & 9 & $7,3 \%$ \\
\hline 2 & $\begin{array}{c}\text { Thúy tinh thế } \\
\text { nhân tạo }\end{array}$ & 11 & 8,9 \\
\hline 3 & $\begin{array}{c}\text { Xơ hóa co kéo } \\
\text { vòng xé bao }\end{array}$ & 65 & $52,8 \%$ \\
\hline 4 & Đục bao sau & 85 & $69,1 \%$ \\
\hline 5 & Rách bao sau & 4 & $3,3 \%$ \\
\hline
\end{tabular}

Có 5 biến chứng phát hiện ở thời điểm nghiên cứu: Đục bao sau là biến chứng gặp nhiều nhất với $69,1 \%$, tiếp đến là xơ hóa co kéo vòng xé bao $52,8 \%$, rách bao sau là $3,3 \%$.

\section{BÀN LUÂN}

4.1. Đặc điểm chung của bệnh nhân. Trong nghiên cứu của chúng tôi, tuổi trung bình của bệnh nhân là $71,70 \pm 7,75$, thấp nhất $56 \mathrm{cao}$ nhất 88 tuổi. Số bệnh nhân có tuổi trên 60 chiếm tỷ lệ lớn $(91,04 \%)$. Tỷ lệ nam nhỏ hơn nữ tương ứng là $47,8 \%$ so với $52.2 \%$. Nghiên cứu này cho kết quả tương tự như của tác giả Guber và cộng sự năm 2016 [5].

4.2. Hình thái đục thủy tinh thể. Trong nghiên cứu của chúng tôi trong tổng số 123 mắt được nghiên cứu, phần lớn là đục thủy tinh thể do tuổi già 115 mắt $(93,5 \%)$, còn lại là do bệnh lý và Steroid 8 mắt $(6,5 \%)$.

Đục thủy tinh thể tuổi già gặp hình thái đục nhân và đục hoàn toàn là chủ yếu $(93,9 \%)$, và độ IV và độ $V$ chiếm tới $88,1 \%$ (43,9\% và $34,2 \%)$. Đây là nhóm bệnh nhân có nhân đục gần hoàn toàn, khó soi được đáy mắt, vì vậy trong phẫu thuật tỉ lệ biến chứng cao hơn và sử dụng năng lượng phaco lớn hơn cho nên sau mổ hay bị phù mép mổ, khó liền sau mổ.

Kết quả nghiên cứu của chúng tôi cũng tương tự như của Dương Tấn Hùng và cộng sự (2013) 
tại BV Trung Ương Huế [6].

4.3. Đặc điểm thị lực tại thời điểm khám bệnh. Tại thời điểm nghiên cứu, có tới 106 mắt $(86,2 \%)$ thị lực trên $20 / 40$, trong đó nhóm 20/40-20/30 là 44,7\%. Đặc biệt nhóm $\geq 20 / 25$ chiếm 41,5\%. Nhóm 20/60-20/50 là 9,8\%, Chỉ có 1 mắt $(0,8 \%)$ có thị lực <20/200. Như vậy thị lực được phục hồi sau phẫu thuật nhanh chóng và được duy trì $100 \%$ bệnh nhân thi lực sau phẫu thuật tăng hơn so với trước phẫu thuật. Điều đó cho thấy hiệu quả của việc khám và sàng lọc lựa chọn bệnh nhân trước phẫu thuật của chúng tôi tương đối tốt.

Kết quả này cũng được khẳng định trong phần lớn các nghiên cứu khác về hiệu quả của phẫu thuật phaco.Trần Thị Phương Thu và cộng sự (2009) đã báo cáo về 49 bệnh nhân bị đục thủy tinh thể tuổi già tại Bệnh Viện Mắt TP Hồ Chí Minh cho kết quả khả quan với $89,8 \%$ bệnh nhân có thị lực sau phẫu thuật từ $5 / 10$ trở lên, chỉ có $10,02 \%$ bệnh nhân có thị lực 4/10 [7].

4.4. Độ loạn thị trước phấu thuật và tại thời điểm khám. Theo kết quả nghiên cứu này, tai 2 thời điểm trước phẫu thuat và hiên tai không có mắt nào có độ loạn thị giác mạc trên 2.00 Diop. Số mắt có độ loạn 1.00- $\leq 2.00$ Diop trước phẫu thuật là 31 mắt $(25,2 \%)$, tại thời điểm nghiên cứu là 46 mắt (37,4\%). Độ loạn thị giác mạc tại thời điểm nghiên cứu cao hơn trước phẫu thuật: loạn thị giác mạc trung bình tại thời điểm nghiên cứu là $0,86 \pm 0,38 \mathrm{D}$, loạn thị trung bình trước phẫu thuât $0,62 \pm 0,39$. Như vậy sau phẫu thuật mức độ loạn thị thay đổi không nhiều. Đây là một kết quả rất đáng ghi nhận so với các nghiên cứu khác tại Việt Nam. Theo chúng tôi, có thể viêc sử dung dao 2,8 tao đường mổ nhỏ là đóng góp quan trọng nhất trong việc hạn chế tăng độ loạn thị trong phẫu thuật phaco.

4.5. Triệu chứng chủ quan sau phẫu thuật. Tại thời điểm nghiên cứu, cảm giác ruồi bay và lóa mắt là hai triệu chứng hay gặp nhất lần lượt là $73,9 \%$ và $42,3 \%$. Triệu chứng khác chủ yểu là ngứa mắt cộm chiếm $8,9 \%$. Nhìn vật rung rinh xảy ra ít nhất với 1 mắt $(0,8 \%)$. Có 14 mắt $(11,4 \%)$ không có triệu chứng. Theo chúng tôi, phần lớn bệnh nhân sau phẫu thuật có hiện tương lóa mắt và ruồi bay, điều này lí giải vì sau phẫu thuật bệnh nhân bị cận thị và loạn thị chiếm tỉ lệ cao kèm theo bệnh nhân có độ tuổi trung bình cũng cao, 100\% bệnh nhân thủy tinh thể tạo đơn tiêu, không có chức năng lọc ánh sáng xanh, tia UV, vì vậy bệnh nhân nhìn lóa mắt chiếm tỉ lệ nhiều.
4.5 Biến chứng sau phẫu thuật. Trong nghiên cứu này có 5 biến chứng phát hiện ở thời điểm nghiên cứu: Đục bao sau là biến chứng gặp nhiều nhất với $69,1 \%$, tiếp đến là xơ hóa co kéo vòng xé bao $52,8 \%$, biến chứng về thủy tinh thể nhân tạo là 8,9\%, đồng tử méo 7,3\%. Rách bao sau là ít nhất với 3,3\%. Về biến chứng của thủy tinh thể nhân tạo, không có mắt nào bị kẹt và lệch. Trong số mắt lệch tâm thì lệch ít chiếm cao hơn so với lệch nhiểu tương ứng 9 mắt $(7,3 \%)$ và 2 mắt $(1,6 \%)$.

Tỷ lệ biến chứng rách bao sau trong nghiên cứu của chúng tôi có cao hơn so với nghiên cứu của Vũ Mạnh Hà (2014): thủng bao sau thoát dịch kính chiếm $1,9 \%$ nhưng có tỷ lệ phù hoàng điểm dạng nang 2,83\% [8]. Theo chúng tôi, nguyên nhân của tỷ lệ những biến chứng trên là do bệnh nhân tuổi cao, thủy tinh thể đục hoàn toàn, nhân cứng độ IV-V... dẫn đến khó khăn trong thì chẻ nhân

\section{KẾT LUẬN}

- Tuổi trung bình của bệnh nhân là $71,70 \pm$ 7,75 , tỷ lệ nam nhỏ hơn nữ tương ứng là $47,8 \%$ so với $52.2 \%$.

- Trong tổng số 123 mắt được nghiên cứu, phần lớn là đục thủy tinh thể do tuổi già 115 mắt $(93,5 \%)$, còn lại là do bệnh lý và Steroid 8 mắt $(6,5 \%)$.

- Thị lực sau chỉnh kính có tới 106 mắt $(86,2 \%)$ thị lực trên $20 / 40$, trong đó nhóm 20/40-20/30 là 44,7\%.

- Số mắt có độ loạn 1.00- $\leq 2.00$ Diop trước phẫu thuật là 31 mắt $(25,2 \%)$, tại thời điểm nghiên cứu là 46 mắt $(37,4 \%)(p<0,05)$.

- Cảm giác ruồi bay và lóa mắt là hai triệu chứng hay gặp nhất lần lượt là 91 mắt $(73,9 \%)$ và 52 mắt $(42,3 \%)$. Triệu chứng khác chủ yếu là ngứa mắt cộm chiếm $8,9 \%$. Nhìn vật rung rinh xảy ra ít nhất với 1 mắt $(0,8 \%)$. Có 14 mắt $(11,4 \%)$ không có triệu chứng.

- Có 5 biến chứng phát hiện ở thời điểm nghiên cứu: Đục bao sau là biến chứng găp nhiều nhất với $69,1 \%$, tiếp đến là xơ hóa co kéo vòng xé bao $52,8 \%$, rách bao sau là $3,3 \%$.

\section{TÀI LIÊU THAM KHẢO}

1. Đố Như Hơn (2014), Nhãn Khoa tập $2, N X B Y$ học, Hà Nội, tr 190-226.

2. Kelman C.D (2002), Cataract surgery and intraocular lenses: A 21st-century perspective, 2nd ed, Archives of Ophthalmology, 120 (7), 1002-1003.

3. Nguyển Hữu Quốc Nguyên, Tôn Thị Kim Thanh (2004), Phẫu thuật Phaco nhập môn, NXB Y hoc.

4. Kwitko ML,Kelman CD (1998), The History of Modern Cataract Surgery, Kugler. 
5. Guber I, Mouvet $V$, Bergin $C$ et al (2016), Clinical Outcomes and Cataract Formation Rates in Eyes 10 Years After Posterior Phakic Lens Implantation for Myopia. JAMA Ophthalmol.

6. Dương Tấn Hùng và Nguyễn Hữu Quốc Nguyến (2013), Đánh giá kết quả phẫu thuật PHACO điêuu trị đực thủy tinh thể băng đường rạch trên giác mạc phía thái dương. Tạp chí Y học thực hành, $870(\dot{5}), 30-31$.
7. Trân Thị Phương Thu, Võ Đức Dũng, Dương Quốc Cường, et al. (2009), Đánh giá kết quả phâuu thuât phaco tai khoa Bán công - Bênh viên Mắt TP. HCM, Tạp chí Y học Thành phố Hồ Chí Minh, 13 (1).

8. Vũ Mạnh Hà (2014), Nghiên cứu phẫu thuật đục thể thuỷ tinh bằng hai phương pháp phaco và đường rach nhỏ tai tỉnh Hà Giang, Luân án Tiến sĩ, Trường Đ̇ại học Y Hà Nội.

\section{ĐÁNH GIÁ KẾT QUẢ SỐNG THÊM SAU ĐIỀU TRI UNG THƯ ĐẠI TRÀNG GIAI ĐOẠN T4 HOẶC N1-2 BẰNG PHẪU THUÂTT CẮT TOÀN BÔ MAC TREO ĐAI TRÀNG VÀ HÓA TRI TẠI KHOA ĐIỀU TRI THEO YÊU CẦU BÊNNH VIỆN K}

\section{TÓM TẮT}

Mục tiêu: Đánh giá kết quả sống thêm sau điều tri ung thư đai tràng giai đoan T4 hoăc N1-2 bằng phẫu thuật cắt toàn bộ mạc treo đại tràng và hóa trị tai khoa Điều trị theo yều câu Bềnh viên $K$. Đối tượng: 50 bệnh nhân được chẩn đoán ung thư đại tràng giai đoan T4 hoăc N1-2 chưa có di căn xa, đước phẫu thuật cắt toàn bộ mạc treo đại tràng và hóa trị tại khoa Điều trị theo yêu cầu Bệnh viện K trong giai đoạn 2017-2019. Kết quả: Tất cả các bệnh nhân trong nghiên cứu được mổ mở, thởi gian mổ trung bình $121,7 \pm 16,9$ phút, thời gian trung tiện trung bình là $3,5 \pm 0,5$ ngày, thời gian nằm viện trung bình là $8,7 \pm 1,1$ ngày. Chiều dài đoạn ruột trung bình là $31,2 \pm 2,4 \mathrm{~cm}$, diện cắt trên trung bình $12,8 \mathrm{~cm}$, diện cắt dưới trung bình $9,9 \mathrm{~cm}$. Số lượng hạch vét được trung bình là $30,9 \pm 19,3$ hạch, trong đó sổ lượng hạch chặng 1 trung bình là 12,3 hạch, hạch chặng 2 là 8,9 hạch, hạch chặng 3 là 5,6 hạch, hạch N2O-2A là 4,1 hạch. $50 \%$ bệnh nhân có di căn hạch với số lượng hạch di căn trung bình cho mối ca là 3,8 hạch, trong 50 bệnh nhân có $40 \%$ có di căn hạch chặng $1,28 \%$ có di căn hạch chặng 2,12\% bệnh nhân có di căn hạch chặng 3 và $6 \%$ có di căn hach nhóm N2O-2A. Khổng gặp các tai biến-biến chứng trong mổ như: tổn thương mạch máu lớn hoăc các tạng lân cân. Một bênh nhân có nhồi máu phội sau mổ đã được can thiệp lấy huyết khối, hâuu phẫu ổn đinh sau 17 ngày, 2 trường hợp bệnh nhân (4\%) có viêm phổi và rối loạn nhịp tim sau mổ (bệnh nhân có bệnh lý hô hấp hoặc tim mạch trước đó) được điều trị nội khoa ổn định. Không gặp trường hợp nào có biến chứng như chảy máu sau mổ,

\footnotetext{
${ }^{1}$ Bệnh viện $K$

${ }^{2}$ Đai hoc Y Hà Nôi

Chịu trách nhiệm chính: Bệnh viện K Email: quochoan201087@gmail.com Ngày nhận bài: 10.9.2021

Ngày phản biên khoa hoc: 27.10.2021

Ngày duyệt bài: 12.11.2021
}

Chử Quốc Hoàn1, Mai Tiến Đạt ${ }^{1}$, Dương Chí Thành ${ }^{1}$, Nguyễn Văn Hiếu ${ }^{1,2}$ rò miệng nối, hẹp miệng nối hoặc chảy máu miệng nối sau mô. $64 \%$ bệnh nhân được hóa trị phác đồ XELOX, $22 \%$ sử dụng phác đồ FOLFOX và $14 \%$ sử dụng phác đồ Capecitabine đơn thuần. Toàn bô bênh nhân đều được hoàn thiện liệu trình hóa trị, không có trường hợp nào phải ngừng điều trị do độc tính. Tất cả bệnh nhân trong nghiên cứu không gặp các biến chứng nă̆ng do hóa trị. Thời gian theo dõi trung bình đến thời điểm hiện tại là 37.1 tháng, ghi nhận 2 trường hợp tái phát chiếm $4 \%$ và 1 tứ vong chiếm $2 \%$. 1 trường hợp tái phát di căn gan và 1 trường hợp tái phát di căn phúc mạc tiểu khung.

Tư khóa: Ung thư đại tràng, Phẫu thuật cắt toàn bộ mạc treo đại tràng, CME.

\section{SUMMARY}

THE RESULTS OF COMPLETE MESOCOLIC EXCISION IN STAGE II,III COLON CANCER TREATMENT AT K HOSPITAL

Objectives: Describe the results of complete mesocolic excision in stage II,III colon cancer treatment at K hospital. Patients and methods: 50 patients was diagnosed stage II,III colon cancer at $\mathrm{K}$ hospital. Result: All patients in this study had opened surgery, the average surgery time was $121,7 \pm 16,9$ minutes, the time to first flatus was $3,5 \pm 0,5$ days, the length of hospital stay was $8,7 \pm 1,1$ days. The average specimen length was $31,2 \pm 2,4 \mathrm{~cm}$, the proximal resection margin was $12,8 \mathrm{~cm}$, the distal resection margin was $9,9 \mathrm{~cm}$. The median number of examined lymph nodes was 30,9 $\pm 19,3$, in which the number of lymph nodes in D1 was 12,3 , lymph nodes in D2 was 8,9, lymph nodes in D3 was 5,6 lymph nodes and N2O-2A lymph nodes were 4,1 nodes. Fifty percent of patients had lymph node metastases with an average of 3,8 lymph nodes per case, in which $40 \%$ had D1 lymph node metastases, $28 \%$ had D2 lymph nodes metastases, $12 \%$ of patients had D3 lymph node metastases and $6 \%$ of N2O-2A lymph node metastases. No complications such as damage to major blood vessels or adjacent organs, bleeding or 